\title{
Bundling Process of Citrulline Polypeptides upon UCST-type Phase
}

\section{Separation}

Shota Fujii ${ }^{\dagger}$, Sotaro Kuroyanagi ${ }^{\dagger}$, Naohiko Shimada, Jun Matsumo, Ji Ha Lee, Rintaro Takahashi,

Atsushi Maruyama*, and Kazuo Sakurai*

†Department of Chemistry and Biochemistry, University of Kitakyushu, 1-1 Hibikino,

Kitakyushu, Fukuoka 808-0135, Japan

‡Department of Life Science and Technology, Tokyo Institute of Technology, 4259 B-57,

Nagatsuta, Yokohama 226-8501, Japan

*Corresponding authour

Table of Contents

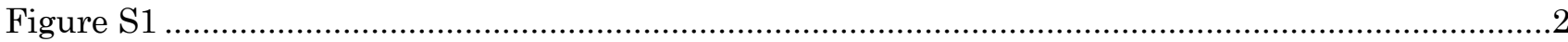

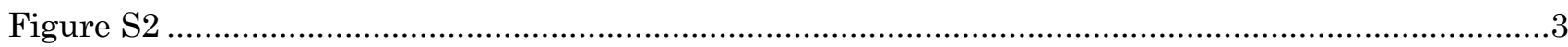

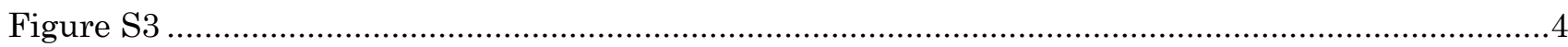

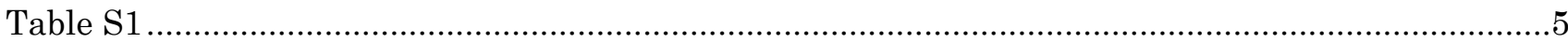

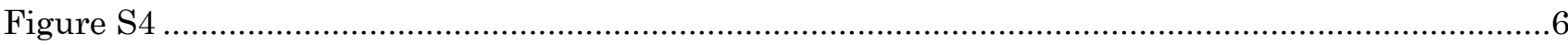


Figure S1

(a)

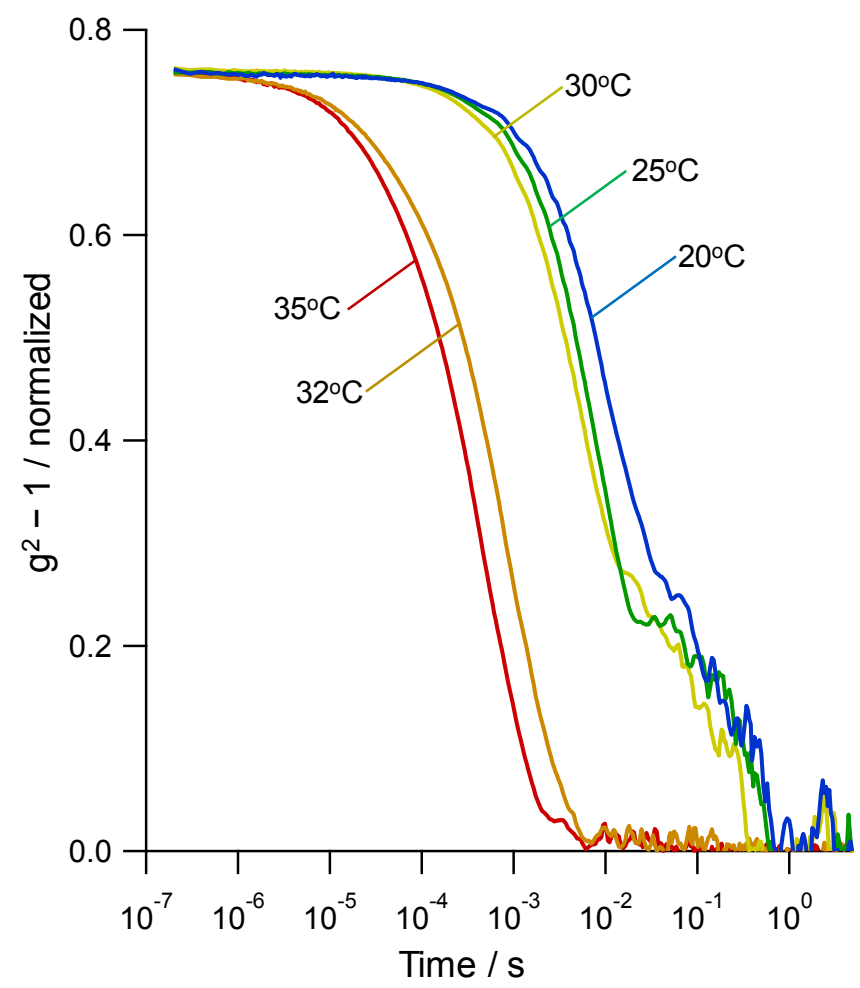

(b)

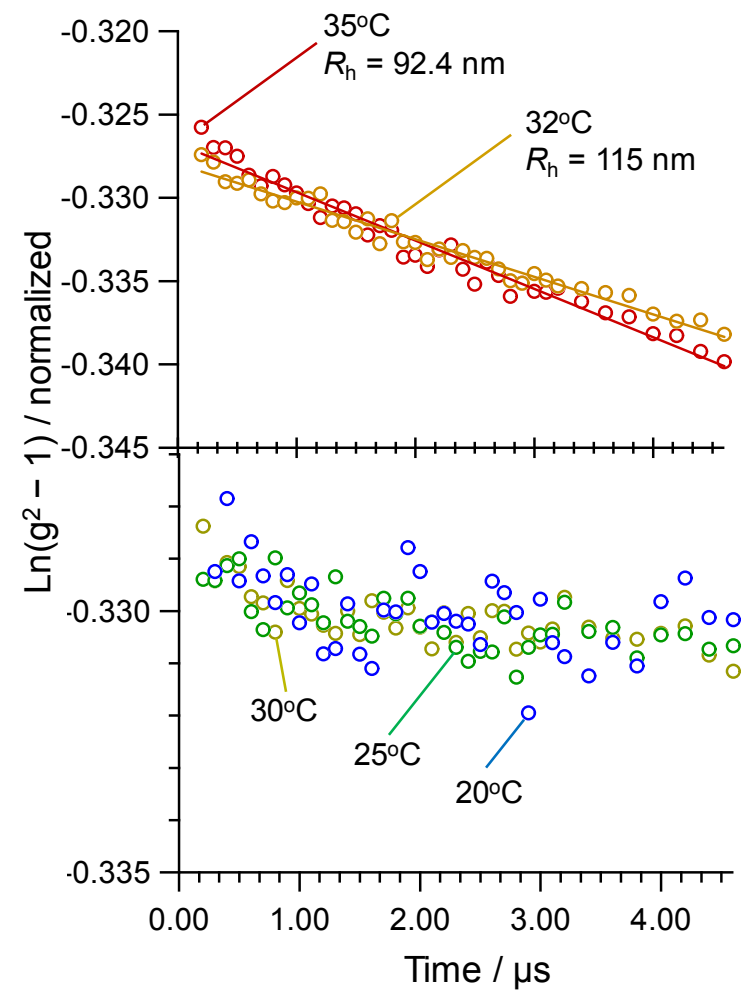

Figure S1. Autocorrelation function $\left[(a) g^{2}-1\right.$ or (b) $\left.\ln \left(\mathrm{g}^{2}-1\right)\right]$ of $\mathrm{P}_{\mathrm{L}} \mathrm{OC}$ in $10 \mathrm{mM}$ HEPES-NaOH $(\mathrm{pH}$ 7.5) containing $150 \mathrm{mM} \mathrm{NaCl}$ at different temperatures. 


\section{Figure S2}

(a)

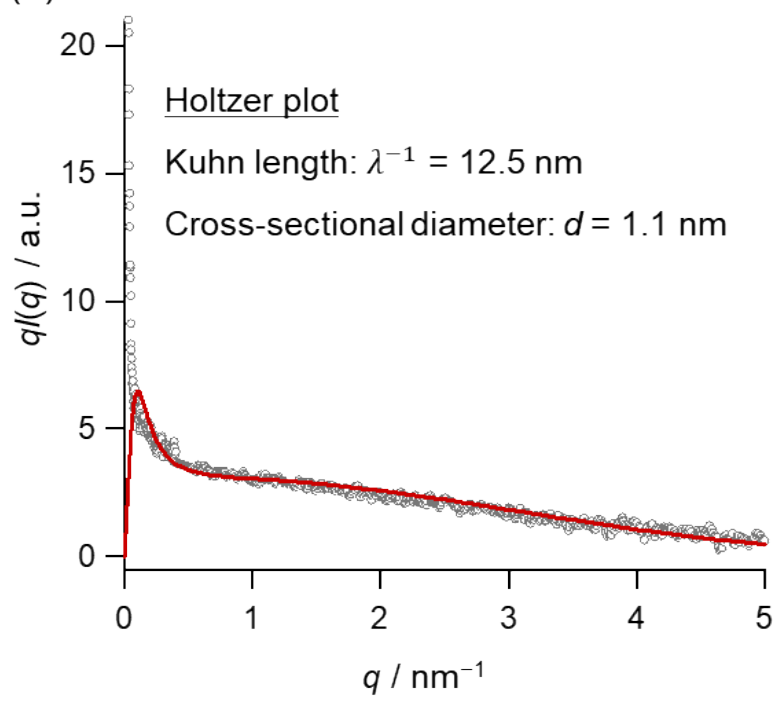

(b)

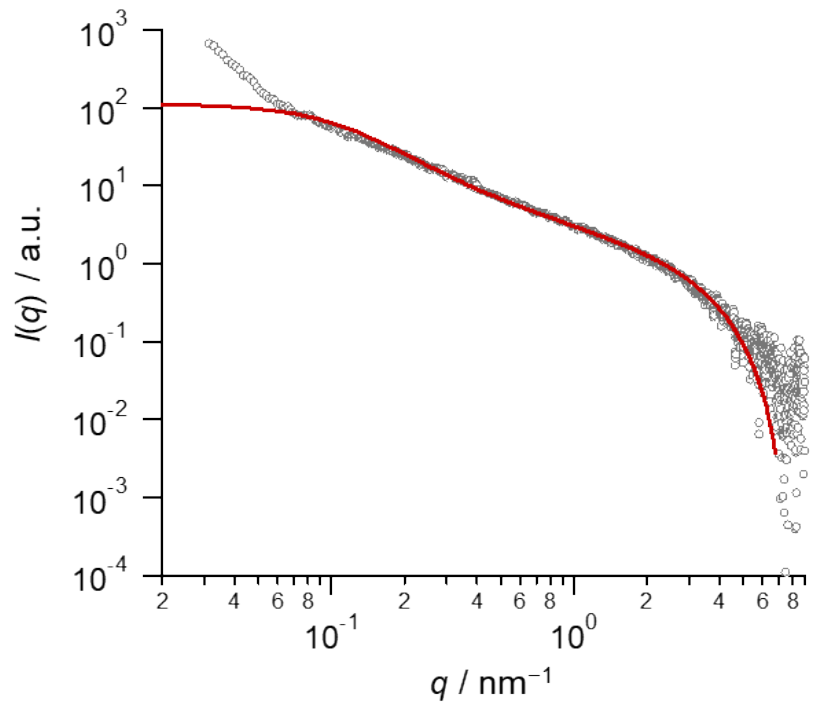

Figure S2. (a) The Holtzer plot for the SAXS profile of $\mathrm{P}_{\mathrm{L}} \mathrm{OC}$ at $35^{\circ} \mathrm{C}$ and comparison with the Norisuye and Nakamura theory ${ }^{1}$ with the indicated Kuhn length $\left(\lambda^{-1}\right)$ values and the cross-sectional diameter $(d)$. (b) Comparing SAXS profile of $\mathrm{P}_{\mathrm{L}} \mathrm{OC}$ at $35^{\circ} \mathrm{C}$ with the calculated fitting curve.

\section{Refereces}

1. Nakamura, Y.; Norisuye, T., Scattering function for wormlike chains with finite thickness. Journal of Polymer Science Part B: Polymer Physics 2004, 42 (8), 1398-1407. 
Figure S3

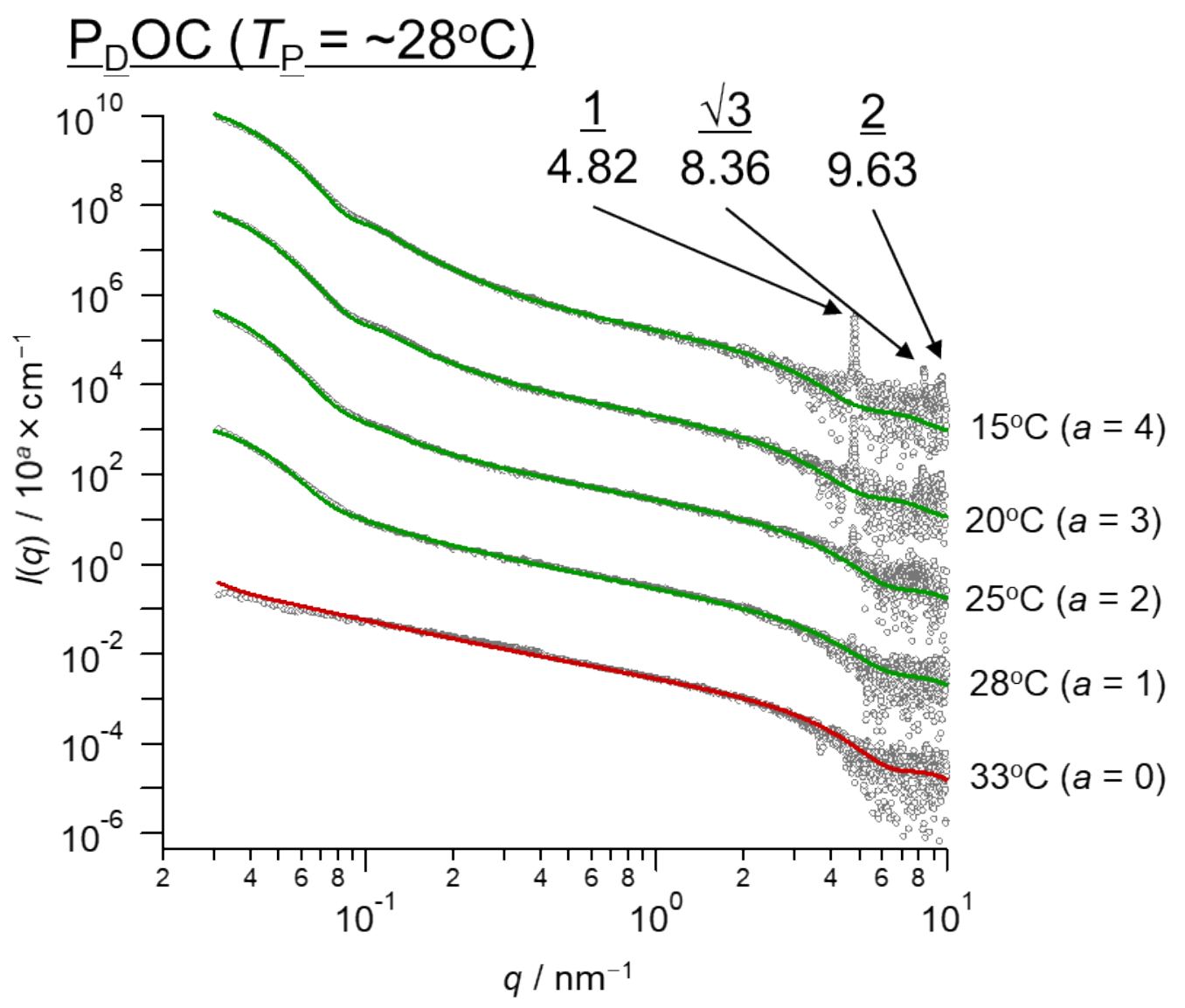

Figure S3. SAXS profiles of $1.0 \mathrm{mg} / \mathrm{mL} P_{\mathrm{D}} \mathrm{OC}\left(M_{\mathrm{w}}=8.3 \times 10^{4} \mathrm{~g} / \mathrm{mol}\right.$, citrulline content $=91.0 \%$, $\left.T_{\mathrm{p}}=28^{\circ} \mathrm{C}\right)$ in $10 \mathrm{mM}$ HEPES-NaOH $(\mathrm{pH} 7.5)$ containing $150 \mathrm{mM} \mathrm{NaCl}$ at different temperatures. The red and green curves were calculated using the modified UF model described in eq. (1) or (2), respectively. 
Table S1

Table S1. Fitting Parameters for the SAXS Profiles of $\mathrm{P}_{\mathrm{D}} \mathrm{OC}$ in $10 \mathrm{mM}$ HEPES-NaOH (pH 7.5) Containing $150 \mathrm{mM} \mathrm{NaCl}$ at Different Temperatures Using the Modified UF Models

\begin{tabular}{|c|c|c|c|c|c|}
\hline $\begin{array}{c}\text { Temp. } \\
{\left[{ }^{\circ} \mathrm{C}\right]}\end{array}$ & $\begin{array}{c}R_{\mathrm{c}} \\
{[\mathrm{nm}]}\end{array}$ & $\begin{array}{c}R_{\mathrm{g}} \\
{[\mathrm{nm}]}\end{array}$ & $D_{\mathrm{M}}$ & $\begin{array}{c}R_{\mathrm{S}} \\
{[\mathrm{nm}]}\end{array}$ & $\sigma^{*} / R_{\mathrm{s}}$ \\
\hline 33 & 0.55 & 100 & 1.7 & - & - \\
\hline 28 & 0.60 & 68 & 1.7 & 40 & 0.38 \\
\hline 25 & 0.62 & 68 & 1.7 & 42 & 0.29 \\
\hline 20 & 0.72 & 68 & 1.7 & 42 & 0.24 \\
\hline 15 & 0.72 & 68 & 1.7 & 45 & 0.22 \\
\hline
\end{tabular}

*We assumed that the size distribution can be described by Gaussian function and $\sigma$ is the standard deviation of the spherical aggregation. 
Figure S4

(a)

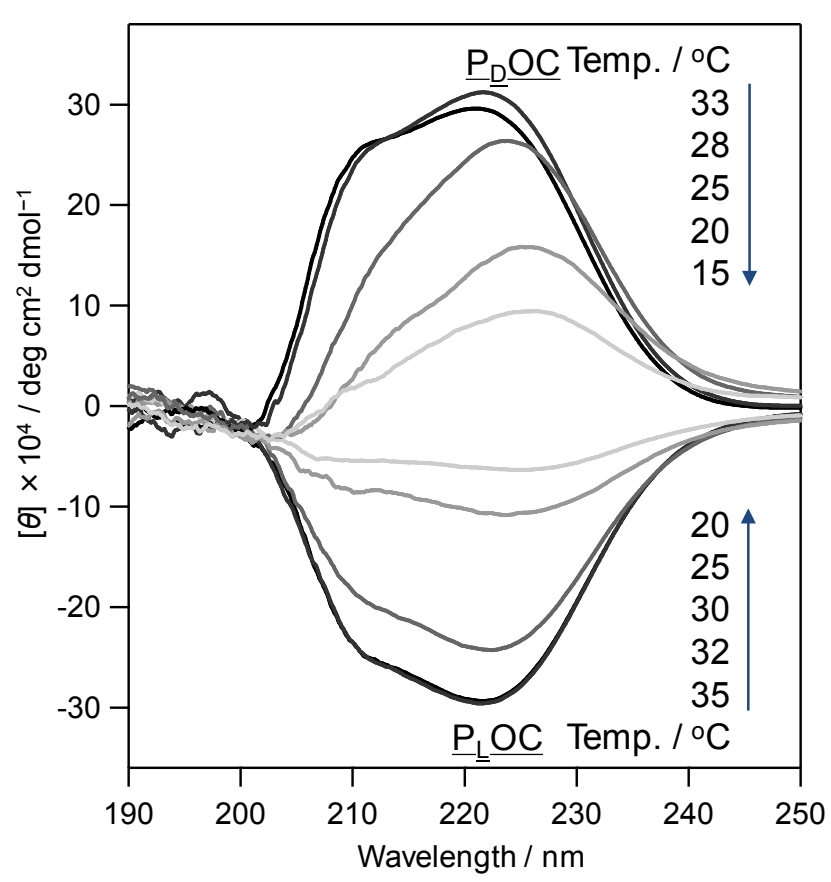

(b)

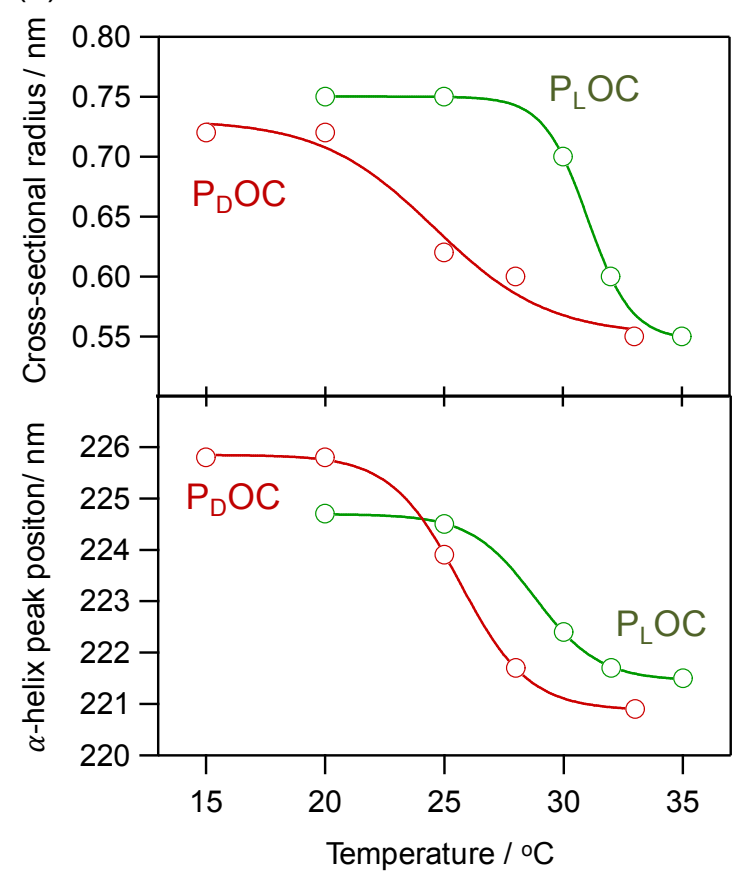

Figure S4. (a) CD spectra of $\mathrm{P}_{\mathrm{L}} \mathrm{OC}\left(M_{\mathrm{w}}=1.02 \times 10^{5} \mathrm{~g} / \mathrm{mol}\right.$, citrulline content $\left.=92.5 \%, T_{\mathrm{p}}=30^{\circ} \mathrm{C}\right)$ and $\mathrm{P}_{\mathrm{D}} \mathrm{OC}\left(M_{\mathrm{w}}=8.3 \times 10^{4} \mathrm{~g} / \mathrm{mol}\right.$, citrulline content $\left.=91.0 \%, T_{\mathrm{p}}=28^{\circ} \mathrm{C}\right)$ in $10 \mathrm{mM} \mathrm{HEPES}-\mathrm{NaOH}(\mathrm{pH} 7.5)$ containing $150 \mathrm{mM} \mathrm{NaCl}$ at different temperatures. (b) Temperature dependence of the cross-sectional radius of $\alpha$-helix determined by SAXS analysis and peak top position relating to the $\alpha$-helix structure. 